\title{
Cytomegalovirus infection presenting as a colonic mass in a patient with acquired immunodeficiency syndrome
}

This article was published in the following Dove Press journal:

International Medical Case Reports Journal

20 July $201 \mathrm{I}$

Number of times this article has been viewed

\author{
Dhyan Rajan' \\ Robin Jacob' \\ Sadat Rashid ${ }^{2}$ \\ Magdalene Vardaros ${ }^{2}$ \\ Anastasiya Pigal ${ }^{3}$ \\ Wondwossen Gebre \\ Kaleem Rizvon ${ }^{2}$ \\ Krishnaiyer Subramani ${ }^{2}$ \\ Umeko Takeshige ${ }^{2}$ \\ Paul Mustacchia ${ }^{2}$ \\ 'Department of Internal Medicine, \\ ${ }^{2}$ Department of Gastroenterology, \\ ${ }^{3}$ Department of Pathology, Nassau \\ University Medical Center, East \\ Meadow, New York, NY, USA
}

\begin{abstract}
Cytomegalovirus (CMV) infection of the gastrointestinal tract occurs in both immunocompromised and immunocompetent hosts. Often presenting as ulcerative lesions, CMV infection rarely presents as a mass lesion in the gastrointestinal tract. We present a case of a discrete colonic mass caused by CMV infection in a patient with acquired immunodeficiency syndrome (AIDS). This case illustrates that an infectious process such as CMV should be considered along with malignancy as the etiology of a mass lesion present in the gastrointestinal tract of patients with AIDS.
\end{abstract}

Keywords: pseudotumor, colonic mass, opportunistic infection, ganciclovir

\section{Introduction}

Cytomegalovirus (CMV) infection of the gastrointestinal tract is seen in up to $40 \%$ of patients with acquired immunodeficiency syndrome (AIDS). ${ }^{1}$ Although frequently presenting as ulcerative lesions resulting in erosive esophagitis, gastritis, or colitis, nonulcerative presentations of $\mathrm{CMV}$ in the gastrointestinal tract have been reported., ${ }^{2,3}$ Kaposi's sarcoma and lymphoma are the most common cause of discrete mass lesions in the alimentary tract of individuals with AIDS. ${ }^{1,4}$ We present a rare case of a discrete colonic mass secondary to CMV infection in a patient with AIDS.

\section{Case report}

A 38-year-old Hispanic male with a past medical history of AIDS on highly active antiretroviral therapy (HAART), diabetes mellitus, and stage 5 chronic kidney disease on hemodialysis presented to the medical emergency room with complaints of bright red blood per rectum and abdominal pain. He had noticed bright red blood intermixed with stool present with every bowel movement for two days. He also experienced dull intermittent pain in the right upper quadrant of the abdomen during this period. The patient denied any unintentional weight loss, anorexia, diarrhea, fatigue, or tenesmus. Physical examination was remarkable for pallor and mild tenderness in the right upper quadrant without rigidity or guarding. Digital rectal examination did not reveal any hemorrhoids, mass lesions, or evidence of gross bleeding.

Laboratory evaluation was significant for hemoglobin of $8 \mathrm{~g} / \mathrm{dL}$ with hematocrit of $24 \%$. His plasma human immunodeficiency virus RNA level was undetectable, and $\mathrm{CD} 4^{+} \mathrm{T}$ lymphocyte count was 410 cells $/ \mathrm{mm}^{3}$. Computed tomography of the abdomen revealed no significant abnormalities.
Correspondence: Dhyan Rajan 220I Hempstead Turnpike, East Meadow, New York I I554, NY, USA

$\mathrm{Tel}+\mathrm{I} 516572650 \mid$

Fax + I 5165725609

Email drajan@numc.edu 
The patient was admitted to the medical floor where his HAART was continued, and he underwent esophagogastroduodenoscopy and colonoscopy. The esophagogastroduodenoscopy was unremarkable, but colonoscopy revealed a $4 \times 5 \mathrm{~cm}$ friable mass with mucosal ulcerations in the ascending colon near the hepatic flexure suspicious for neoplasm (Figure 1). Multiple biopsies were obtained and sent for histopathologic evaluation. Surgical pathology showed colonic mucosa with extensive granulation tissue and acute inflammatory cells suggestive of colitis. Within the granulation tissue were endothelial cells and fibroblasts with basophilic intranuclear inclusion bodies suggestive of CMV infection (Figure 2) which was confirmed by immunohistochemistry staining for CMV antibodies (Figure 3). Special staining for acid-fast bacilli and fungi was negative. There was no histological evidence of spindle cells with neovascularization, or lymphocytic proliferation with plasmacytic differentiation suggestive of Kaposi's sarcoma or lymphoma, respectively. The patient was treated with intravenous ganciclovir for six weeks. Repeat colonoscopy after treatment showed complete resolution of the mass (Figure 4), with significant clinical improvement.

\section{Discussion}

CMV is a double-stranded DNA virus of the Herpesviridae family that frequently infects both immunocompetent and immunocompromised hosts. Serologic evidence of prior infection can be seen in nearly $60 \%$ of all individuals, often remaining clinically silent. ${ }^{2}$

In immunocompromised individuals, especially those with AIDS, CMV infection may involve different organ systems, including the gastrointestinal tract, resulting in

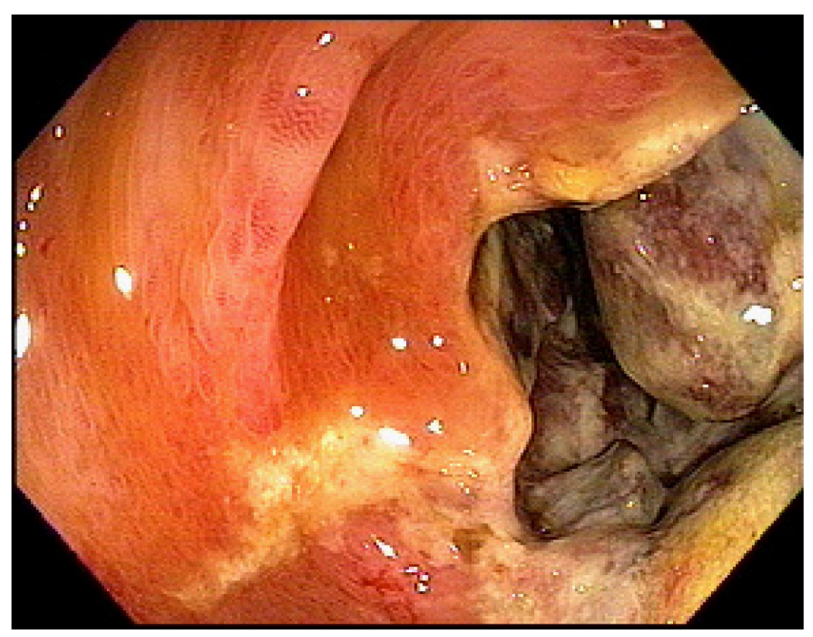

Figure I Colonoscopy revealing a friable mass in the ascending colon suspicious for neoplasm.

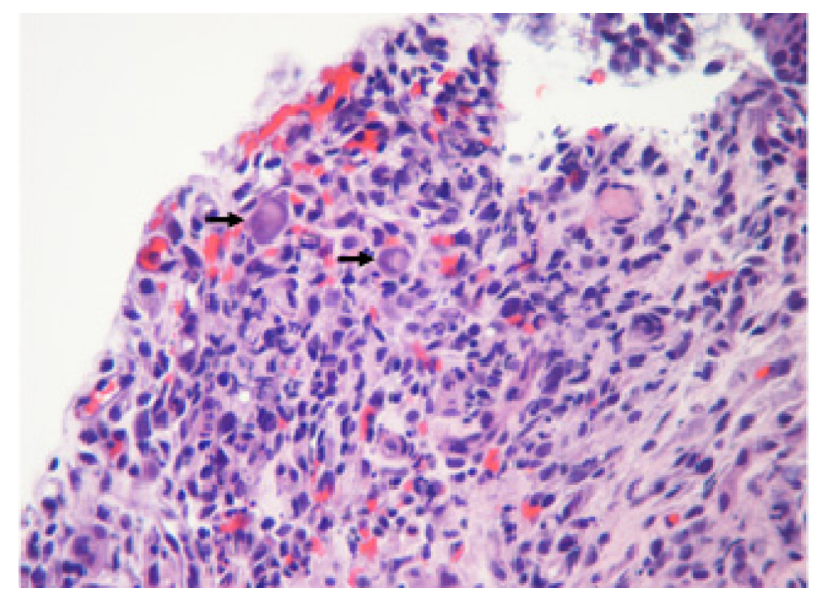

Figure 2 Hematoxylin and eosin staining of the colonic mass. Note the larger cytomegalovirus-infected cells (arrows) within extensive granulation tissue. Basophilic nuclear inclusion bodies are noted, indicative of active cytomegalovirus replicating nucleoprotein cores.

significant morbidity. Despite the declining incidence of most opportunistic gastrointestinal infections in patients with AIDS since the advent of HAART, CMV coinfection of the gastrointestinal tract is still clinically present. ${ }^{5}$

CMV infection is present in the alimentary tract of approximately $15 \%-40 \%$ of individuals with AIDS. ${ }^{1}$ The gastrointestinal manifestations may occur with reactivation of latent disease, secondary to diminishing immune function. ${ }^{1,2}$ The most frequent clinical presentations of gastrointestinal infection with CMV include erosive esophagitis and colitis. Rarely, bowel obstruction, perforation, toxic megacolon, and gastrointestinal hemorrhage have been reported, often requiring surgical intervention. ${ }^{6}$ Colonic involvement of CMV may present clinically with fever, abdominal pain, profuse diarrhea, weight loss, and

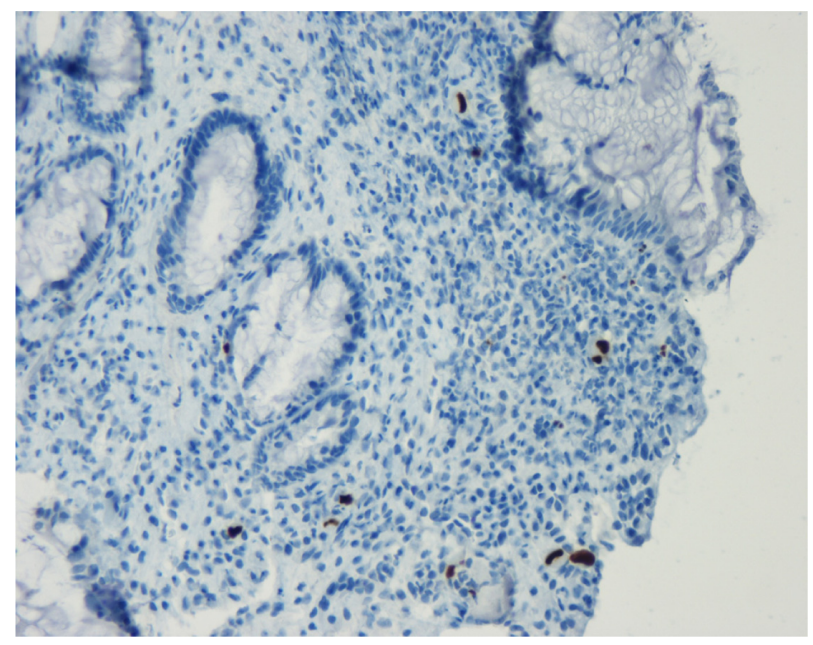

Figure 3 Positive immunohistochemistry of the colonic mass with a specific anticytomegalovirus antibody, confirming the diagnosis of cytomegalovirus infection. 


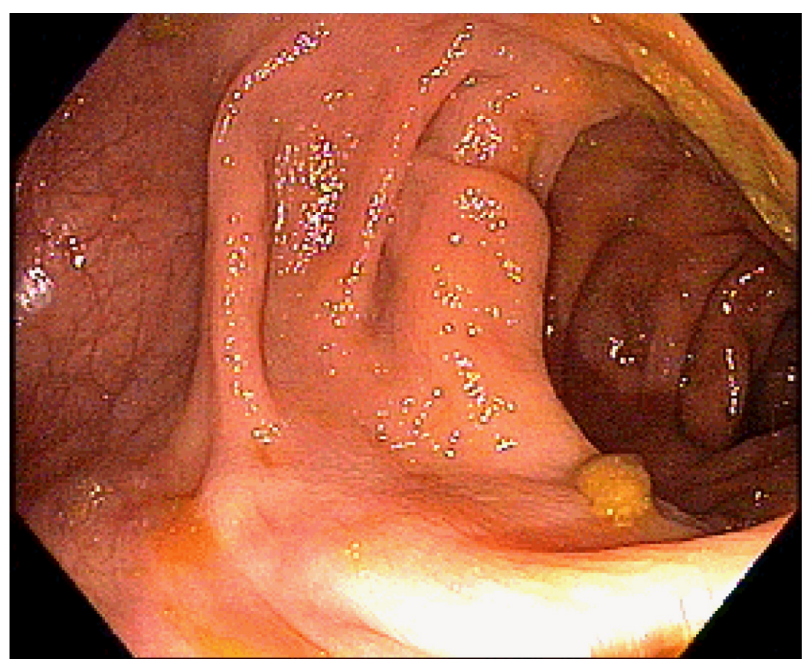

Figure 4 Complete resolution of the colonic mass after ganciclovir treatment.

gastrointestinal hemorrhage, often warranting endoscopic evaluation for prompt diagnosis.

Endoscopic findings of CMV infection may demonstrate mucosal erythema, erosions, ulcerations, and submucosal hemorrhage. ${ }^{6} \mathrm{CMV}$ infection in the colon may also mimic ischemic colitis in appearance due to interstitial necrosis of colonic mucosa, secondary to involvement of endothelial cells. ${ }^{8}$ Colonic involvement of CMV can be diffuse or limited to one particular part of the bowel. In nearly $25 \%$ of individuals with CMV colitis, colonic mucosa may appear endoscopically normal, so biopsies should be taken from multiple areas of bowel if CMV infection is suspected. ${ }^{6}$ Rarely does colonic involvement of CMV result in a discrete mass lesion. ${ }^{1,4}$

A discrete mass lesion of the gastrointestinal tract in patients with AIDS is frequently caused by a malignant neoplasm. The most frequent malignancies of the gastrointestinal tract in patients with AIDS are Kaposi's sarcoma and lymphomas, accounting for nearly $95 \%$ of all identified malignancies. ${ }^{9}{ }^{9}$ Infrequent causes of gastrointestinal mass lesions in patients with AIDS may include infectious processes, such as tuberculosis, toxoplasmosis, histoplasmosis, and CMV infection. ${ }^{11-14}$

Fan et al retrospectively analyzed 25 cases of patients with AIDS who underwent endoscopic evaluation for gastrointestinal complaints, such as abdominal pain, diarrhea, and hemorrhage. Of the 25 patients, six were found to have discrete colonic masses. Despite similar clinical and endoscopic presentations, three patients were found to have malignancy, and the other three were found to have a mass lesion caused by an infectious etiology based on histopathologic evaluation. This study emphasizes that, despite malignancy being a common cause of colonic mass lesions in patients with AIDS, a thorough endoscopic evaluation with histological examination of the lesions is needed to rule out a possible infectious etiology. ${ }^{14}$

Colonic mass lesions due to malignancy that are noted on endoscopy are often indistinguishable from those caused by CMV infection. Kaposi's sarcoma and lymphoma often appear as erythematous submucosal nodules with superficial ulcerations. However, they may also appear as a solitary colonic mass. In rare instances, vascular proliferation of CMV infection results in a mass-like lesion grossly resembling a neoplasm on endoscopic evaluation. ${ }^{15}$

The diagnosis of CMV infection of the colon relies heavily on histolopathological examination, and may reveal a variety of findings. Cells infected by CMV are often larger than adjacent cells (cytomegaly), and may have a thickened nuclear membrane along with granular intracytoplasmic inclusions. ${ }^{16}$ Basophilic intranuclear inclusion bodies surrounded by a clear halo, giving rise to the characteristic "owl's eye" appearance of the cell, are suggestive of active CMV replicating nucleoprotein cores. ${ }^{16}$ Despite typical histological findings suggestive of CMV infection, immunohistochemistry is often required to confirm the diagnosis. Kandiel et al suggest that nearly $40 \%$ of patients with gastrointestinal CMV infection do not demonstrate typical inclusion bodies on standard hematoxylin and eosin staining, and the use of immunohistochemical staining can increase sensitivity to greater than $90 \% .{ }^{16,17}$

Medical management is the mainstay of treatment for CMV infection in the gastrointestinal tract. Ganciclovir and foscarnet are antiviral agents demonstrated to be active against CMV, and clinical improvement of patients treated may be observed in up to $90 \%$ of cases. ${ }^{6}$ In the case described, ganciclovir therapy resulted in marked clinical improvement and complete resolution of the colonic mass on subsequent colonoscopy.

\section{Conclusion}

Suspicion of CMV infection should heighten in immunocompromised hosts presenting with gastrointestinal complaints. Although frequently caused by neoplasm, infectious processes such as CMV must also be considered as a cause of a discrete colonic mass in patients with AIDS. If CMV infection is identified, medical therapy often results in significant clinical improvement, and possible resolution of a colonic mass if present.

\section{Disclosure}

The authors report no conflicts of interest in this work. 


\section{References}

1. Rich J, Crawford J, Kazanjian S, Kazanjian P. Discrete gastrointestinal mass lesions caused by cytomegalovirus in patients with AIDS: Report of three cases and review. Clin Infect Dis. 1992;15:609-614.

2. Danenberg A, Margulis S. Cytomegalovirus infection of the gastrointestinal tract in AIDS. Gastroenterology. 1987;92:1362.

3. Klatt E, Shibata D. Cytomegalovirus infection in the acquired immunodeficiency syndrome. Arch Pathol Lab Med. 1988;112:540-544.

4. Sang-II L, Jun-Seok P, Taek-Gu L, et al. Ulcerofungating rectal mass caused by cytomegalovirus infection in a patient with AIDS. J Korean Soc Coloproctol. 2007;23:270-273.

5. Monkemuller K, Lazenby A, Lee D, Loudon R, Wilcox C. Occurrence of gastrointestinal opportunistic disorders in AIDS despite the use of highly active antiretroviral therapy. Dig Dis Sci. 2005;50:230-240.

6. Corman M. Colonic manifestations of human immunodeficiency virus infection. In: Colon and Rectal Surgery. New York, NY: Lippincott, Williams \& Wilkins; 2005.

7. Mohan H, Bal A, Garg S, Dalal U. Cytomegalovirus-associated pseudotumor simulating gastric malignancy in acquired immunodeficiency syndrome: A case report and review of literature. Jpn J Infect Dis. 2007; 60:134-136.

8. Domenech E, Vega R, Ojanguren I, et al. Cytomegalovirus infection in ulcerative colitis: A prospective, comparative study on prevalence and diagnostic strategy. Inflamm Bowel Dis. 2008;14:1373-1379.
9. Chandrasoma P. Nonneoplastic diseases of the colon. In: Gastrointestinal Pathology. Stamford, CT: Appleton and Lange; 1999.

10. Friedman S. Neoplasms of the gastrointestinal tract and hepatobiliary system in AIDS. Semin Gastrointest Dis. 1991;2:62-74.

11. Lee S, Hall-Craggs M, Lees W. Appendix mass in AIDS. Br J Radiol. 1987;60:1030-1031.

12. Balthazar E, Gordon R, Hulnik D. Ileocecal tuberculosis: CT and radiologic evaluation. AJR Am J Roentgenol. 1990;154:499-503.

13. Graham B, Mckinsey D, Driks M, Smith D. Colonic histoplasmosis in acquired immunodeficiency syndrome: Report of two cases. Dis Colon Rectum. 1991;34:185-190.

14. Fan X, Scott L, Qui S. Colonic mass in patients with AIDS: An expanded differential diagnosis. Gastrointest Endosc. 2008;67:325.

15. Classen M, Tytgant G, Lightdale C. Colorectal disorders. In: Gastroenterological Endoscopy. New York, NY: Thieme Publishing Group; 2010.

16. Nguyen M, Bradford K, Zhang X, Shih D. Cytomegalovirus reactivation in ulcerative colitis patients. Ulcers. 2011:1-7.

17. Kandiel A, Lashner B. Cytomegalovirus colitis complicating inflammatory bowel disease. Am J Gastroenterol. 2006;101:2857-2865.
International Medical Case Reports Journal

\section{Publish your work in this journal}

The International Medical Case Reports Journal is an international, peer-reviewed open-access journal publishing original case reports from all medical specialties. Previously unpublished medical posters are also accepted relating to any area of clinical or preclinical science. Submissions should not normally exceed 2,000 words or

\section{Dovepress}

4 published pages including figures, diagrams and references. The manuscript management system is completely online and includes a very quick and fair peer-review system, which is all easy to use. Visit $\mathrm{http}: / / \mathrm{www}$.dovepress.com/testimonials.php to read real quotes from published authors. 